\title{
Inter-annual variation in the diet, provisioning and growth of Cassin's auklet at Triangle Island, British Columbia: responses to variation in ocean climate
}

\author{
April Hedd ${ }^{1, *}$, John L. Ryder ${ }^{1}$, Laura L. Cowen ${ }^{2}$, Douglas F. Bertram ${ }^{1,3}$ \\ ${ }^{1}$ Centre for Wildlife Ecology, Department of Biological Sciences, and ${ }^{2}$ Department of Statistics and Actuarial Sciences, \\ Simon Fraser University, 8888 University Drive, Burnaby, British Columbia V5A 1S6, Canada \\ ${ }^{3}$ Environment Canada, Canadian Wildlife Service, Pacific and Yukon Region, RR1 5421 Robertson Rd, Delta, \\ British Columbia V4K 3N2, Canada
}

\begin{abstract}
We studied parental provisioning and chick growth rates of Cassin's auklet Ptychoramphus aleuticus at Triangle Island, British Columbia, Canada, from 1996 to 1999. Auklet reproductive performance and ocean climate conditions during these years were highly variable, and reflected in the diet composition. Chick growth was maximal when the diet was predominated by copepods, in particular Neocalanus cristatus. Provisioning and growth were high in 1999, intermediate in 1997 and poor in 1998. Exceptional was 1996, when growth was low but provisioning rates were high. Provisioning and growth were depressed late in 1997 and throughout 1998 when larval rockfish Sebastes spp. (5200 cal g ${ }^{-1}$ ) replaced N. cristatus $\left(6236 \mathrm{cal} \mathrm{g}^{-1}\right.$ ) in the nestling diet. Zooplankton surveys indicated that $N$. cristatus was substantially more abundant in May 1999 than in May 1998, and during 1999 the auklets foraged in areas with the highest concentrations of copepods. Through impacts on prey availability, variation in ocean climate affects the reproductive performance of Cassin's auklet. Performance tends to be favorable in years when spring is late and cold, and poor when spring is early and warm. Equations for predicting food delivery rates from $24 \mathrm{~h}$ mass changes of chicks were highly year-specific, precluding their application in other years or at other sites where Cassin's auklets breed. Between-year differences were also found in relationships between adult provisioning and chick growth. These were strongly positively related in 1999, positively related in 1996 and 1997, but unrelated in 1998; differences attributed to the magnitude of temporal variation in the nestling diet. Finally, we detected annual differences in parental response to chick needs. In 1999, parents delivered more food to chicks in poor condition and less to those in better condition, responses not observed in 1998. Different responses between years may have reflected variation in the availability of prey.
\end{abstract}

KEY WORDS: Cassin's auklet · Ptychoramphus aleuticus $\cdot$ Provisioning $\cdot$ Growth $\cdot$ Diet $\cdot$ Copepods · Neocalanus cristatus $\cdot$ Rockfish $\cdot$ Euphausiid $\cdot$ Ocean climate variation

Resale or republication not permitted without written consent of the publisher

\section{INTRODUCTION}

Cassin's auklet Ptychoramphus aleuticus is a small, widely distributed alcid that breeds along the west coast of North America from Alaska to Baja California,

\footnotetext{
*Present address: 4 Hammond Est., Portugal Cove-St. Philips, Newfoundland A1M 2Y7, Canada.

E-mail: ahedd@attcanada.net
}

Mexico; an estimated $75 \%$ of the world's population breeds in British Columbia, Canada (Manuwal \& Thoresen 1993). The diet of breeding birds varies geographically, but consists of zooplankton, larval fishes and cephalopods throughout its range (Manuwal 1974, Vermeer 1981, 1985, Ainley et al. 1996, Sydeman et al. 1997). In British Columbia, copepods, euphausiids and small fish predominate the food delivered to nestlings (Vermeer 1981, 1985, Burger \& Powell 1990). Adults 
forage offshore during the day, returning to their single chick at night to deliver meals carried in a specialized throat pouch (Manuwal 1974). Adults make, at most, 1 visit to the colony each night (Triangle Island Research Station unpubl. data). Young depart the colony at approximately $90 \%$ of adult mass after spending an average of $45 \mathrm{~d}$ in the burrow (Vermeer \& Cullen 1982, Vermeer 1987, Morbey \& Ydenberg 1997, Triangle Island Research Station unpubl. data).

The present study provides a detailed examination of provisioning and growth for nestling Cassin's auklets on Triangle Island, British Columbia, where longterm population studies are ongoing. An estimated 547000 pairs of Cassin's auklets bred at this site in 1989, constituting the world's largest population (Rodway et al. 1990). Oceanographically, Triangle Island is situated at the northern end of the Coastal Upwelling Domain, a domain where circulation is dominated by the California current (Ware \& McFarlane 1989). Since the mid-1950s the biomass of zooplankton within the California current system has declined by $80 \%$ (Roemmich \& McGowan 1995). During this period, Cassin's auklet populations in the Gulf of the Farallones, California, have declined by approximately $50 \%$ (Ainley et al. 1994, 1996). Within the 1990s major variations in the annual reproductive performance of Cassin's auklet were observed at Triangle Island (Bertram et al. 2001), and in combination with low adult survival they also suggest a population decline at this site (Bertram et al. 2000, Canadian Wildlife Service unpubl. data). Annual differences in reproductive performance at Triangle Island have been linked to variations in ocean climate (Bertram et al. 2001). An annual index of spring timing for the British Columbia coast, modeled using average weekly sea surface temperatures (SSTs) between 1 January and 31 August, was significantly related to chick growth for Cassin's auklet. Chick growth was poor in years when ocean warming occurred relatively early (i.e. years with an 'early spring') and when SSTs in April were warm. Bertram et al. (2001) suggested that variability within the physical environment influenced the timing of peak availability of the birds' main prey species, the copepod Neocalanus cristatus, in surface waters. Variation in ocean climate is therefore reflected in the reproductive performance of Cassin's auklet as productivity and survival are strongly linked with the availability of prey (see also Ainley et al. 1996).

Here we used periodic weighing to facilitate a detailed investigation of the patterns of provisioning and growth of Cassin's auklet nestlings during $4 \mathrm{yr}$, 1996 to 1999, when ocean climate conditions and reproductive performance were highly variable. Our main objectives were to quantify how the rates and patterns of chick provisioning and growth varied both within and between years, to determine how performance was influenced by variation in the nestling diet composition, and to investigate whether diet and reproductive performance co-varied with annual changes in ocean climate. At a finer scale, we tested: (1) if equations developed from overnight weighing in 1 year could be used to predict provisioning rates from daily mass changes recorded in other years, (2) if chick condition on Night $x$ influenced the quantity of food received on Night $x+1$, and (3) if rates of adult provisioning influenced the growth of their chicks.

\section{MATERIALS AND METHODS}

Provisioning and growth. This study was conducted at West Bay, Triangle Island $\left(50^{\circ} 52^{\prime} \mathrm{N}, 129^{\circ} 05^{\prime} \mathrm{W}\right)$, British Columbia, Canada, during the chick-rearing periods of Cassin's auklet, in 1996 to 1999. After hatching commenced, burrows within the designated study plot were searched until 40 to 42 chicks were found. Chicks were weighed $( \pm 1 \mathrm{~g})$ with a spring balance and their flattened wingchords were measured $( \pm 1 \mathrm{~mm})$. Chick age was estimated from the length of the wingchord on the initial measurement day (Day 0), using calibration of wing length against age for known-aged chicks (Triangle Island Research Station unpubl. data). Only chicks judged to be $25 \mathrm{~d}$ or less on Day 0 (i.e. wingchord $\leq 82 \mathrm{~mm}$ ) were aged using this technique, as measurements from older chicks were considered unreliable for aging. Wingchord was measured daily in 1998 and 1999. For the next $30 \mathrm{~d}$ (47 d in 1996), or until they fledged, disappeared or died in the burrow, chicks were weighed daily at 16:00 h. Chicks lost from the sample were not replaced. At Triangle Island chicks fledge, on average, at $45 \mathrm{~d}$ of age (range 40 to 57 d; Vermeer 1987, Morbey \& Ydenberg 1997, Triangle Island Research Station unpubl. data).

Cassin's auklets feed their chicks only at night, returning to the colony after sunset and departing before sunrise (Manuwal \& Thoresen 1993, Bertram et al. 1999). On 3 occasions in May and June of 1996 and 1997 (roughly on Days 5/6, 15/16 and 25/26), chicks were weighed at 22:30 and at 05:00 $\mathrm{h}$ in addition to the daily weighing at 16:00 h. During the first overnight weighing session in 1998, chicks were weighed at $4 \mathrm{~h}$ intervals (20:00, 00:00, 04:00, 08:00 and 12:00 h), while during the remainder they were weighed at 22:00, 02:00 and 06:00 h. The latter protocol was adopted again in 1999. Increases in chick mass between overnight weighings resulted from feedings by either one or both parents. We used the sum of such positive mass increments (SUMs) to estimate the total quantity of food delivered overnight (termed the provisioning rate, $\mathrm{g} \mathrm{d}^{-1}$ ), after correcting for the mass lost between 
weighings due to respiration and excretion (Ricklefs 1984, Ricklefs et al. 1985). Parental attendance was not monitored independently in this study, and because such information has been found to significantly alter estimates of both feed size and feeding frequency (Granadeiro et al. 1999), we made no attempt to divide overnight SUMs into presumed 'single' or 'double' feeds (see also Phillips \& Hamer 2000). The weighings took up to $1.5 \mathrm{~h}$ to complete, and chicks were always weighed in the same order. The gular pouches of nestlings were often extremely distended at night but, aside from a partial regurgitation in 1997, the overnight weighings did not cause chicks to lose food.

We used multiple regression to explain variation in the amount of food fed to nestlings based upon their mass, age, wingchord (in 1998 and 1999), and their net $24 \mathrm{~h}$ mass change (NET) for up to 3 previous nights (i.e. NET1, NET-2, NET-3; Ricklefs 1987). Separate equations were developed for each year, and these were used to estimate the quantity of food delivered to chicks on nights when overnight weighings were not conducted. The same chicks were measured each day, so the daily measurements could not be considered as independent. When assessing inter- and intra-annual variation in provisioning rates, data were blocked and averaged in periods of $10 \mathrm{~d}$ (according to chick age) and analyses were performed on the average values. Repeatedmeasures ANOVAs would have been preferable, but the staggered start and end ages for chicks precluded this option, and between-subjects ANOVAs were used.

Following Hamer \& Hill (1993) and Hamer \& Thompson (1997), an index of chick body condition was developed in both 1998 and 1999 (when wingchord was measured daily). Nestling body condition was estimated from the residuals of the regression of body mass on wingchord (expressed as a proportion of the predicted value). Linear regressions were performed separately for each year, to determine if chick condition after feeding influenced the quantity of food received the subsequent night. To test if daily weighing of chicks affected their growth, we used 1-way ANOVA to compare their mass at 25, 35 and $41 \mathrm{~d}$ to the mass of chicks studied for population level estimates of growth (sequential treatment). The later were weighed at $0,5,10,25$, and $35 \mathrm{~d}$ and then every $2 \mathrm{~d}$ until fledging. To control for potential seasonal effects of hatch date on body mass, age-specific comparisons were date-constrained (by between $12 \mathrm{~d}$ in 1998 and $20 \mathrm{~d}$ in 1996). Fledging was defined as the departure from the burrow of older than $40 \mathrm{~d}$ chicks. Departures were confirmed by re-checking the burrow $2 \mathrm{~d}$ later, and the final set of measurements was considered coincident with fledging.

Food sampling. Each year, at intervals of approximately $10 \mathrm{~d}$, food loads intended for nestlings ( $\mathrm{n} \leq$
12 per night) were collected at night from incoming adults. Samples were collected from mid-May to the end of June each year. As adults returned to the colony they were trapped using soft plastic 'pheasant nets' erected at the base of the nesting slopes. The contents of each adult's gular pouch was collected by inverting the bird over a plastic funnel attached to a preweighed container, and gently massaging the throat area until food was no longer forthcoming. Birds were handled for $<5 \mathrm{~min}$, and released immediately after sampling. Samples were weighed and preserved in 5 to $10 \%$ formalin in the field. Food sampling was not conducted in areas where other experimental treatments were underway.

In the laboratory, samples were transferred to a series of stacked sieves $(\geq 0.1 \mathrm{~mm})$, and repeated washings with water removed the preservative. Each species or taxonomic group was identified (by Moira Galbraith at the Institute of Ocean Sciences, British Columbia), counted, and transferred to its own preweighed aluminum dish. After removing excess water with absorbent paper, a wet weight for each species/ group was obtained. Data are presented here as a percentage of the wet mass, and were arcsine-transformed prior to analysis.

Unless otherwise indicated, data are presented as the mean $\pm 1 \mathrm{SD}$, and a $\mathrm{p}<0.05$ was adopted to indicate statistical significance.

\section{RESULTS}

Study dates and sample sizes were as follows: from 21 May to 6 July 1996, 1639 weights were obtained from 42 Cassin's auklet chicks. Likewise from 26 May to 25 June 1997, 2 June to 2 July 1998 and 9 June to 9 July 1999, 1256, 1140 and 1369 weights were obtained, respectively, from a total of 40 chicks each year. Three days into the study in 1997, a parent at one burrow was flushed and eaten by a peregrine falcon, Falco peregrinus, while at another burrow the chick suffered a broken leg at $30 \mathrm{~d}$. Data from these burrows were subsequently excluded. Known fledging rates for daily-weighed chicks were $64 \%$ (21 of 33) in 1996, 83\% (15 of 18) in 1997, 12\% (3 of 25) in 1998 , and $95 \%$ (16 of 17 ) in 1999, rates similar to those for control nests in all years except 1998 (65, 84, 47 and $89 \%$, respectively). Nestlings weighed daily were significantly lighter than those from sequential treatments both early in 1997 (by $10 \mathrm{~g}$ or $7 \%$ of the fledging mass at $25 \mathrm{~d}$ ) and throughout 1999 (by $20 \mathrm{~g}$ [11\% of fledging mass] at both 25 and $35 \mathrm{~d}$, and by

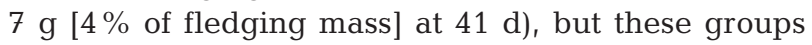
were of similar mass at all ages in 1996 and 1998 (Table 1). 
Table 1. Ptychoramphus aleuticus. Comparison of the average mass in $\mathrm{g} \pm \mathrm{SD}$ (n) of nestlings weighed daily (Daily) with those weighed at longer intervals (Sequential). Bold indicates significant differences between the groups

\begin{tabular}{|c|c|c|c|c|c|c|c|}
\hline \multirow{2}{*}{$\begin{array}{l}\text { Age } \\
\text { (d) }\end{array}$} & 1996 & \multicolumn{2}{|c|}{1997} & \multicolumn{2}{|c|}{1998} & \multicolumn{2}{|c|}{1999} \\
\hline & Sequential & Daily & Sequential & Daily & Sequential & Daily & Sequential \\
\hline \multirow[t]{2}{*}{25} & $102 \pm 19.3(35) \quad 108 \pm 19.4(20)$ & $130 \pm 20.5(39)$ & $140 \pm 13.8(22)$ & $116 \pm 17.6(25)$ & $114 \pm 21.3(35)$ & $133 \pm 11.7(36)$ & $153 \pm 12.7(36)$ \\
\hline & $F_{1,53}=0.97, \mathrm{p}=0.330$ & $F_{1,59}=4.32$, & $\mathrm{p}<0.05$ & $F_{1,58}=0.17$, & $p=0.684$ & $F_{1,70}=47.09$ & $\mathrm{p}<0.0001$ \\
\hline \multirow[t]{2}{*}{35} & $114 \pm 17.4(34) \quad 120 \pm 16.6(19)$ & $142 \pm 20.3(34)$ & $145 \pm 22.9(22)$ & $116 \pm 19.0(20)$ & $120 \pm 18.2(27)$ & $161 \pm 11.4(35)$ & $182 \pm 15.4(34)$ \\
\hline & $F_{1,51}=1.67, \mathrm{p}=0.203$ & $F_{1,54}=0.17$, & $p=0.683$ & $F_{1,45}=0.41$, & $p=0.524$ & $F_{1,67}=38.41$, & $\mathrm{p}<0.0001$ \\
\hline \multirow[t]{2}{*}{41} & $118 \pm 17.6(33) \quad 116 \pm 17.8(17)$ & $146 \pm 15.9(29)$ & $148 \pm 18.1(20)$ & $120 \pm 15.0(18)$ & $124 \pm 17.8(28)$ & $169 \pm 11.4(33)$ & $176 \pm 14.1(28)$ \\
\hline & $F_{1,48}=0.16, \mathrm{p}=0.687$ & $F_{1,47}=0.13$, & $p=0.718$ & $F_{1,44}=0.58$, & $p=0.451$ & $F_{1,59}=4.20$ &, $\mathrm{p}<0.05$ \\
\hline
\end{tabular}

\section{Chick growth}

In each year, Cassin's auklet chicks increased rapidly in mass from hatching to approximately $15 \mathrm{~d}$ of age (Fig. 1). Thereafter, the rates and patterns of chick growth were highly variable between years. Overall, growth was high in 1999, poor in both 1996 and 1998, and intermediate in 1997 (Fig. 1). Annual differences were apparent by $20 \mathrm{~d}\left(F_{3,104}=9.57, \mathrm{p}<0.0001\right)$, with chicks lighter in both 1996 and 1998 than in either 1997 or 1999 (Tukey's honestly significant difference [HSD] test, $\mathrm{p}<0.01)$. Differences between years persisted through to fledging ( $45 \mathrm{~d}_{;} F_{3,74}=38.64, \mathrm{p}<0.0001$ ), but the patterns altered. $45 \mathrm{~d}$ old chicks were significantly heavier in 1999 than in any other year, while those from 1997 were only heavier than those from 1996 (Tukey's HSD, p < 0.01). Fledging mass also differed among years $\left(F_{3,59}=38.79, \mathrm{p}<0.0001\right)$, being greater in $1999(162 \pm 10.0 \mathrm{~g}, \mathrm{n}=26)$ than in either $1996(130 \pm$ $11.3 \mathrm{~g}, \mathrm{n}=21)$ or 1997 (148 $\pm 9.8 \mathrm{~g}, \mathrm{n}=13)$, and also

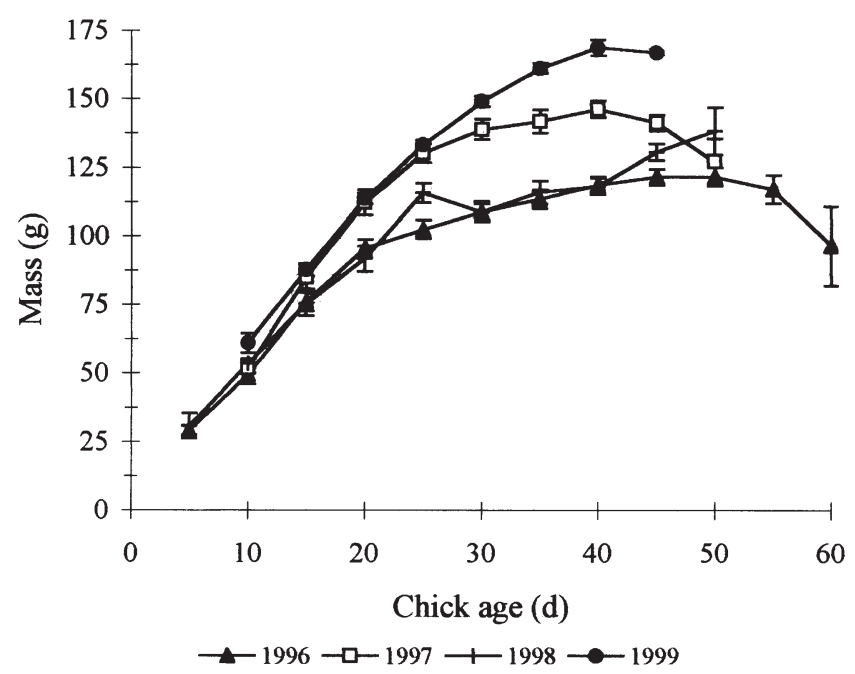

Fig. 1. Ptychoramphus aleuticus. Mean growth in mass $( \pm \mathrm{SE})$ of the daily weighed chicks, 1996 to 1999 . Data were plotted only when $\mathrm{n} \geq 2$ for a particular age class greater in 1997 than 1996 (Tukey's HSD, p < 0.01). Chicks fledged light in 1998 as well $(146 \pm 4.4 \mathrm{~g}, \mathrm{n}=3)$ but probably due to the small sample size (owing to extensive mortality), this was not statistically distinct from other years. In 1996 fledging age was significantly greater than in other years $\left(F_{3,57}=15.85, \mathrm{p}<\right.$ 0.0001: 1996, $51 \pm 3.5 \mathrm{~d}, \mathrm{n}=21 ; 1997,45 \pm 2.5 \mathrm{~d}, \mathrm{n}=13$; $1998,48 \pm 4.0 \mathrm{~d}, \mathrm{n}=3 ; 1999,46 \pm 2.1 \mathrm{~d}, \mathrm{n}=24)$.

\section{Chick provisioning}

\section{Estimating rates of mass loss between overnight weighings}

Positive mass increments between overnight weighings underestimate the total food delivered to nestlings by an amount equivalent to the mass lost via respiration and excretion. Therefore, rates of mass loss both prior to and after a feed were examined in relation to chick age, chick mass and the (uncorrected) SUMs, as appropriate. Rates of mass loss were examined both as linear and proportional functions of time [i.e. $\mathrm{g} \mathrm{h}^{-1}$ and $\log$ (initial mass/final mass) $\mathrm{h}^{-1}$ ] using forward stepwise multiple regression. The best predictions were generated using linear mass-loss rates.

Prior to being fed, the rate of mass loss $\left(w_{\text {prior, }}\right.$ in $\mathrm{g} \mathrm{h}^{-1}$ ) was significantly related to both the initial mass and age of the chick as follows:

1996: $\log w_{\text {prior }}=[0.800(\mathrm{SE} \pm 0.175) \times \log$ initial mass $]$

$$
\begin{aligned}
& -1.836(\mathrm{SE} \pm 0.351) \\
r^{2}= & 0.12, \mathrm{n}=108
\end{aligned}
$$

1997: $\log w_{\text {prior }}=[0.987(\mathrm{SE} \pm 0.263) \times \log$ initial mass $]$ $-[0.546(\mathrm{SE} \pm 0.208) \times \log$ age $]$

$$
-1.475(\mathrm{SE} \pm 0.399)
$$

$$
\mathrm{r}^{2}=0.13, \mathrm{n}=62
$$

1998:

$$
\begin{aligned}
W_{\text {prior }}= & {[-0.008(\mathrm{SE} \pm 0.002) \times \text { initial mass }] } \\
& +[0.012(\mathrm{SE} \pm 0.006) \times \text { age }] \\
& -0.326(\mathrm{SE} \pm 0.174) \\
\mathrm{r}^{2}= & 0.11, \mathrm{n}=102
\end{aligned}
$$


1999:

$$
\begin{aligned}
W_{\text {prior }}= & {[-0.010(\mathrm{SE} \pm 0.003) \times \text { initial mass }] } \\
& +[0.018(\mathrm{SE} \pm 0.008) \times \text { age }] \\
& +0.113(\mathrm{SE} \pm 0.244) \\
r^{2}= & 0.13, \mathrm{n}=93
\end{aligned}
$$

Following a feed, the rates of mass loss ( $w_{\text {following, }}$ in $\mathrm{g} \mathrm{h}^{-1}$ ) were higher, and significantly related to either the initial mass and age of the chick and/or the amount of mass gained (uncorrected SUM) during the previous weighing interval. When weighed at $4 \mathrm{~h}$ intervals in 1998 (the only year that weighings were conducted this frequently), the data indicated that rates of mass loss were linear up to $8 \mathrm{~h}$ after feeding, but that the rates decreased significantly 8 to $12 \mathrm{~h}$ after feeding (repeatedmeasures ANOVA; $\left.F_{2,30}=7.14, \mathrm{p}<0.01\right)$. In both 1996 and 1997, when initial (05:00 h) and subsequent (16:00 h) post-feeding measurements were separated by $11 \mathrm{~h}$, the rates of mass loss at $8 \mathrm{~h}$ were predicted knowing that, on average, chicks lose $1.21 \mathrm{~g} \mathrm{~h}^{-1} 8$ to $12 \mathrm{~h}$ after feeding. The 1996 and 1997 equations were developed using the rates predicted at $8 \mathrm{~h}$. Equations for each year are:

1996: $w_{\text {following }}=[-0.010(\mathrm{SE} \pm 0.003) \times$ initial mass $]+$ $[0.024(\mathrm{SE} \pm 0.006) \times$ age $]-[0.086(\mathrm{SE}$ $\pm 0.004) \times$ uncorrected SUM] $-0.015(\mathrm{SE} \pm 0.220)$

$$
\mathrm{r}^{2}=0.84, \mathrm{n}=119
$$

1997: $w_{\text {following }}=[-0.011(\mathrm{SE} \pm 0.002) \times$ initial mass $]+$ $[0.024(\mathrm{SE} \pm 0.007) \times$ age $]-[0.068(\mathrm{SE}$ $\pm 0.005) \times$ uncorrected SUM] $-0.033(\mathrm{SE} \pm 0.287)$

$\mathrm{r}^{2}=0.71, \mathrm{n}=100$

1998: $w_{\text {following }}=[-0.011(\mathrm{SE} \pm 0.006) \times$ initial mass $]-$ $[0.029(\mathrm{SE} \pm 0.010) \times$ uncorrected SUM] $-1.229(\mathrm{SE} \pm 0.696)$

$\mathrm{r}^{2}=0.20, \mathrm{n}=62$

1999: $\mathrm{w}_{\text {following }}=[-0.045(\mathrm{SE} \pm 0.021) \times$ age $]-[0.069(\mathrm{SE}$ $\pm 0.012) \times$ uncorrected SUM] $+0.849(\mathrm{SE} \pm 0.815)$

$\mathrm{r}^{2}=0.34, \mathrm{n}=79$

Regression Eqs. (1) to (8) were used to estimate weight loss between weighings, assuming that feeding occurred halfway between the weighings. These estimates were used to correct each value of SUM, so that the total amount of food delivered to chicks each night (the provisioning rate, $\mathrm{g} \mathrm{d}^{-1}$ ) could be determined.

Calculating overnight food delivery from daytime weighings

Overnight weighings were conducted on 3 nights each year. Following Ricklefs (1987), we used forward stepwise multiple regression to explain variation in SUMs on these nights based upon knowledge of chick mass, age, net $24 \mathrm{~h}$ mass change for up to 3 previous nights and wingchord (in 1998 and 1999). The following equations were developed to estimate the amount of food delivered on days when chicks were weighed only at 16:00 h:

1996: $\begin{aligned} \mathrm{SUM}= & {[0.344(\mathrm{SE} \pm 0.049) \times \text { chick mass }]+[2.360} \\ & (\mathrm{SE} \pm 0.299) \times \mathrm{NET})+[1.057(\mathrm{SE} \pm 0.246) \\ & \times \mathrm{NET}-1]+[0.980(\mathrm{SE} \pm 0.292) \times \mathrm{NET}-2] \\ & +8.895(\mathrm{SE} \pm 5.172) \\ \mathrm{r}^{2}= & 0.51, \mathrm{n}=115\end{aligned}$

1997: $\mathrm{SUM}=[0.234(\mathrm{SE} \pm 0.043) \times$ chick mass $]-[0.307$ $(\mathrm{SE} \pm 0.144) \times$ age $]+[1.618(\mathrm{SE} \pm 0.176) \times$ $\mathrm{NET}]+[0.729(\mathrm{SE} \pm 0.282) \times \mathrm{NET}-1]$ $+[0.582(\mathrm{SE} \pm 0.281) \times \mathrm{NET}-2]$

$+21.636(\mathrm{SE} \pm 5.063)$

$\mathrm{r}^{2}=0.53, \mathrm{n}=95$

1998: $\mathrm{SUM}=[0.555(\mathrm{SE} \pm 0.086) \times$ chick mass $]-[0.302$ $(\mathrm{SE} \pm 0.090) \times$ wingchord $]+[2.581(\mathrm{SE}$ $\pm 0.168) \times \mathrm{NET}]+[0.510(\mathrm{SE} \pm 0.171)$ $\times \mathrm{NET}-1]+[0.283(\mathrm{SE} \pm 0.189) \times \mathrm{NET}-3]$ $+11.544(\mathrm{SE} \pm 4.969)$

$\mathrm{r}^{2}=0.78, \mathrm{n}=89$

1999: $\mathrm{SUM}=[0.907(\mathrm{SE} \pm 0.155) \times$ age $]+[2.412(\mathrm{SE}$ $\pm 0.258) \times \mathrm{NET}]+[0.988(\mathrm{SE} \pm 0.245)$

$\times \mathrm{NET}-1]+15.568(\mathrm{SE} \pm 5.472)$

$\mathrm{r}^{2}=0.55, \mathrm{n}=95$

Overall, Eqs. (9) to (12) were highly year-specific. When used to predict SUMs for years other than those in which the data were collected, the results varied significantly (Table 2). For example, both the 1997 and 1999 equations significantly overestimated the values

\begin{tabular}{|c|c|c|c|c|}
\hline \multirow[t]{2}{*}{ Year } & \multirow{2}{*}{$\begin{array}{l}\text { Equation } \\
\text { tested }\end{array}$} & \multirow{2}{*}{$\begin{array}{l}\text { Difference }(\mathrm{g}) \\
(\text { mean } \pm \mathrm{SD})\end{array}$} & \multicolumn{2}{|c|}{ Statistics } \\
\hline & & & $Z$ & $\mathrm{p}$ \\
\hline \multirow[t]{3}{*}{1996} & 1997 & $10.3 \pm 7.7$ & -28.51 & 0.000 \\
\hline & $1998^{a}$ & - & \multicolumn{2}{|c|}{ - } \\
\hline & 1999 & $0.5 \pm 11.3$ & -2.90 & 0.004 \\
\hline \multirow[t]{2}{*}{1997} & $1998^{a}$ & - & \multicolumn{2}{|c|}{ - } \\
\hline & 1999 & $-0.2 \pm 9.9$ & -1.60 & 0.110 \\
\hline \multirow[t]{2}{*}{1998} & 1997 & $-8.7 \pm 8.9$ & 16.47 & $<0.001$ \\
\hline & 1999 & $3.0 \pm 11.0$ & 5.46 & $<0.001$ \\
\hline \multirow[t]{2}{*}{1999} & 1997 & $1.6 \pm 7.8$ & -5.91 & $<0.001$ \\
\hline & 1998 & $-20.3 \pm 6.8$ & -23.53 & $<0.001$ \\
\hline
\end{tabular}

Table 2. Ptychoramphus aleuticus. Results of Wilcoxon's signedranks test $(Z)$ for similarity of overnight SUMs (sum of positive mass increments) produced from equations developed using data collected in different years 

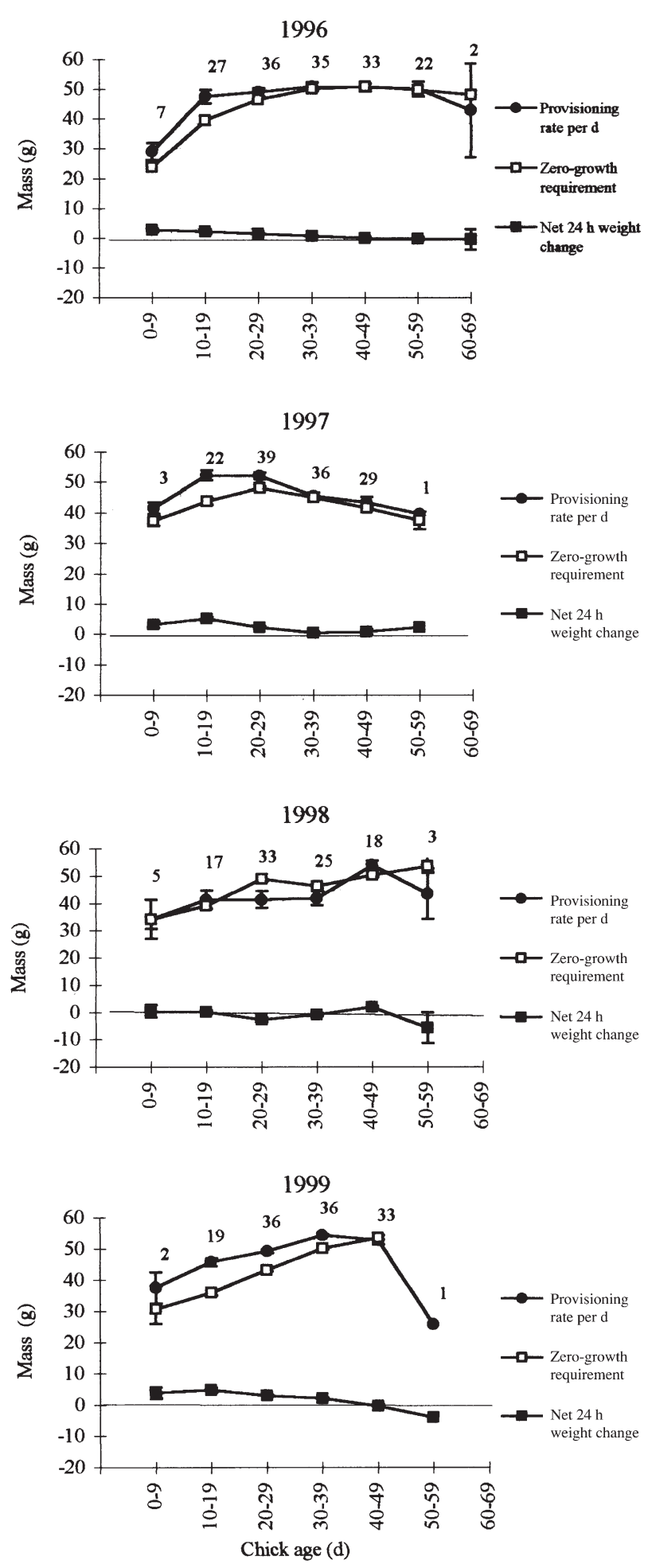

Fig. 2. Ptychoramphus aleuticus. Age-specific variation in daily provisioning rates $(g, \pm S E$, including nights with zero food delivered), mean daily requirements for zero growth $(g, \pm S E)$ and the mean net $24 \mathrm{~h}$ weight change $(g, \pm S E)$ for nestlings, 1996 to 1999. Horizontal lines indicate zero mass change, and sample size (i.e. number of burrows) is indicated above each age class for SUM in 1996. The 1997 equation underestimated the values for SUM in 1998, while the 1999 equation overestimated them. Similarly, the 1997 equation overestimated while the 1998 equation underestimated SUM values produced in 1999 (Table 2). Our analyses demonstrate that in order to use daytime weighings to predict overnight food delivery for Cassin's auklet, it is necessary to develop equations based upon overnight weighing sessions conducted in the same year.

\section{Age-specific patterns of food delivery to chicks}

We estimated that chicks were fed on $100 \%$ of nights in both 1997 (total of 912 chick-nights) and 1999 (913 chick-nights), on $99.6 \%$ (1247 of 1252 chick-nights) of nights in 1996 and on $98 \%$ (599 of 610 chick-nights) of nights in 1998. The overnight weighing protocol adopted part way through 1998 and continued in 1999 (i.e. 22:00, 02:00 and 06:00 h) indicated that $>85 \%$ of feedings occurred between the 22:00 and 02:00 h weighings (87\% in 1998 and $85 \%$ in 1999), while the remainder were delivered between the 02:00 and 06:00 h weighings. Meal sizes from individual adults (estimated from 2 separate mass increments with no adult present at either check) averaged $26 \pm 13.6 \mathrm{~g}$ (range 7 to $52 \mathrm{~g}, \mathrm{n}=20$ ) in 1998 and $27 \pm 24.3 \mathrm{~g}$ (range 2 to $62 \mathrm{~g}, \mathrm{n}=6$ ) in 1999. Average provisioning rates, according to chick age, are shown in Fig. 2 for each year. On average, chicks less than $10 \mathrm{~d}$ of age received 30 to $40 \mathrm{~g} \mathrm{~d}^{-1}$, while 40 to $55 \mathrm{~g} \mathrm{~d}^{-1}$ were delivered to chicks aged 10 to $49 \mathrm{~d}$. There were, however, appreciable inter- and intra-annual differences in provisioning rates, which are shown comparatively in Fig. 3.

Provisioning rates from 0 to $49 \mathrm{~d}$ varied between years $\left(F_{3,471}=3.48, \mathrm{p}<0.05\right)$, and were significantly

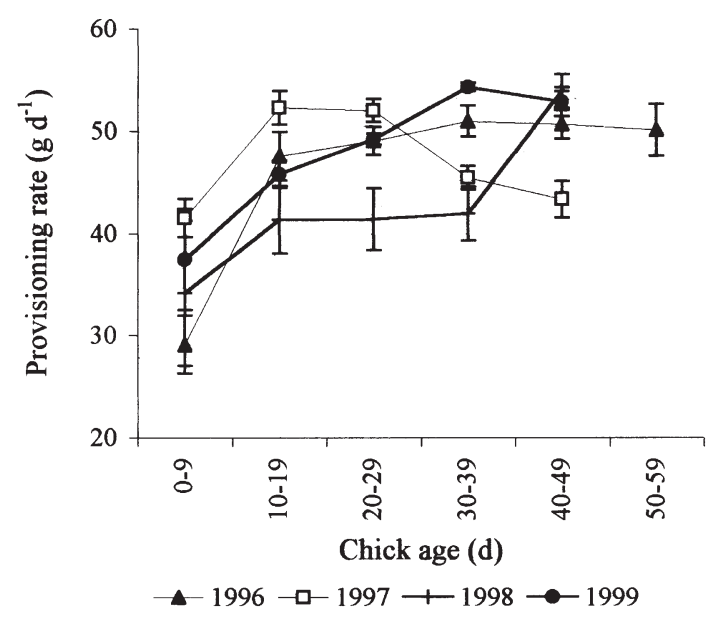

Fig. 3. Ptychoramphus aleuticus. Inter- and intra-annual variation in provisioning rates $\left(\mathrm{g}, \mathrm{d}^{-1}, \pm \mathrm{SE}\right), 1996$ to 1999 
lower in 1998 than in either 1997 or 1999 (Tukey's HSD; $\mathrm{p}<0.01$; Fig. 3). However, within each year provisioning rates also varied significantly across the chick-rearing period (1996: $F_{5,154}=6.71, \mathrm{p}<0.0001$; 1997: $F_{4,124}=8.50, \mathrm{p}<0.0001 ; 1998: F_{4,93}=3.34$, $\mathrm{p}<0.05 ;$ 1999: $F_{4,121}=13.44, \mathrm{p}<0.0001 ;$ Fig. 3). In 1996, provisioning increased significantly through time, and remained relatively stable at $\sim 50 \mathrm{~g} \mathrm{~d}^{-1}$ for chicks $>10$ d of age (Tukey's HSD; p < 0.01). In 1997, provisioning was high from 10 to $29 \mathrm{~d}$, but it decreased between $30 \mathrm{~d}$ and fledging (Tukey's HSD; $\mathrm{p}<0.05)$. In 1998, provisioning was consistently low to $40 \mathrm{~d}$ (averaging $\leq 42 \mathrm{~g} \mathrm{~d}^{-1}$ ), subsequently increasing to $54 \mathrm{~g} \mathrm{~d}^{-1}$ in the $10 \mathrm{~d}$ prior to fledging (Tukey's HSD; $\mathrm{p}<0.05)$. Provisioning was high overall in 1999, increasing progressively from hatching through fledging, with 30 to $49 \mathrm{~d}$ old chicks receiving significantly more food per day than younger chicks (Tukey's HSD; $\mathrm{p}<0.05$, Fig. 3).

\section{Chick maintenance requirements}

The food requirements for zero growth (i.e. for maintaining body mass) were calculated for each age class by linear regression of daily provisioning rates on $24 \mathrm{~h}$ mass changes (Fig. 2; as in Hamer \& Hill 1993, Bolton 1995, Hamer \& Thompson 1997). The $y$-intercept approximates the food required for chicks to maintain body mass. On average, maintenance requirements increased from approximately $32 \mathrm{~g} \mathrm{~d}^{-1}$ when chicks were $<10 \mathrm{~d}$ of age to between 45 and $50 \mathrm{~g} \mathrm{~d}^{-1}$ when they were 20 to $29 \mathrm{~d}$. Requirements remained essentially constant thereafter.

\section{Net 24 h weight change}

Net daily growth corresponds with the degree to which provisioning exceeds the maintenance requirements. In all years the net $24 \mathrm{~h}$ weight change of chicks varied across the rearing period (1996: $F_{5,154}=15.12$, $\mathrm{p}<0.0001 ; 1997: F_{4,124}=10.25, \mathrm{p}<0.0001 ; 1998: F_{4,93}=$ 5.78, p < 0.01; 1999: $\left.F_{4,121}=20.87, \mathrm{p}<0.0001\right)$. In 1997 and 1999, net daily growth peaked at approximately $5 \mathrm{~g} \mathrm{~d}^{-1}$ when chicks were 10 to $19 \mathrm{~d}$ of age, decreasing progressively thereafter (Fig. 2). The pattern in 1996 was similar to 1997 and 1999, but maximal growth was lower reaching only $2.8 \mathrm{~g} \mathrm{~d}^{-1}$ for chicks 10 to $19 \mathrm{~d}$ of age. In 1998, growth rates were maximal between 40 to $49 \mathrm{~d}$. Overall net daily growth varied between years $\left(F_{3,471}=15.39, \mathrm{p}<0.0001\right)$, being lower in 1998 than in all other years (Tukey's HSD; p < 0.0001), and also lower in 1996 than in 1997 and 1999 (Tukey's HSD; p < 0.01).
Regulation of provisioning effort?

In 1998, there was no indication that parents altered provisioning according to the needs of their chick, as chicks that were in good condition at 16:00 h received more food later in the evening, while those in poor condition received less $\left(r^{2}=0.110, n=481, p<0.0001\right)$. The opposite was observed in 1999, when adults appeared to deliver food based upon chick needs. Chicks in good condition at 16:00 $\mathrm{h}$ received less food, while those in poor condition tended to receive more food later in the evening (chicks 0 to $30 \mathrm{~d}, \mathrm{r}^{2}=0.033, \mathrm{n}=406, \mathrm{p}<0.001$; chicks 30 to $\left.50 \mathrm{~d}, \mathrm{r}^{2}=0.009, \mathrm{n}=470, \mathrm{p}<0.05\right)$. Chick condition seemed to have little influence on the frequency with which food was delivered, as chicks were generally fed each night (98\% of nights in 1998 and $100 \%$ of nights in 1999), but we have no information on the behaviour of individual parents.

\section{Inter- and intra-annual variation in nestling diet}

Copepods, euphausiids and fishes together predominated in the food delivered to nestling Cassin's auklets, contributing 90 to $99 \%$ by overall wet mass (Table 3 ). The relative importance of these prey groups varied across years (copepods, $F_{3,194}=14.18, \mathrm{p}<0.0001$; euphausiids, $F_{3,194}=43.10, \mathrm{p}<0.0001$; fishes, $F_{3,194}=23.00$, $\mathrm{p}<0.0001$ ), with substantial reproductive consequences, as chick growth was maximal when copepods predominated in the diet. Neocalanus cristatus (particularly final stage [C5] copepodites) was the most important species consumed, contributing $>99 \%$ to the biomass of copepods delivered to chicks each year. Copepods were more important to the diet in both 1997 and 1999 than in either 1996 or 1998 (Tukey's HSD; p < 0.001, Fig. 4). In the absence of copepods, euphausiids (including Euphausia pacifica, Thysanoessa spinifera and T. inspinata) predominated in the diet in 1996 and, overall, this group was significantly more important in 1996 than in subsequent years (Tukey's HSD; $\mathrm{p}<0.0001$ ). Euphausiids also figured prominently in 1999 (significantly more so than in

Table 3. Ptychoramphus aleuticus. General composition of the food delivered to nestlings between mid-May and end of June 1996 to 1999. Data are expressed as percent wet mass

\begin{tabular}{|lrrrr|}
\hline Prey group & 1996 & 1997 & 1998 & 1999 \\
\hline Copepods & 29.8 & 61.5 & 34.9 & 55.7 \\
Euphausiids & 61.6 & 6.8 & 10.2 & 30.0 \\
Fishes & 2.1 & 30.2 & 44.5 & 9.4 \\
Carideans & 0.5 & 0.1 & 0.9 & 3.3 \\
Amphipods & 1.7 & 0.1 & 7.2 & 1.1 \\
Crabs & 4.3 & 1.0 & 1.6 & 0.0 \\
Other prey & 0.1 & 0.2 & 0.7 & 0.5 \\
\hline
\end{tabular}



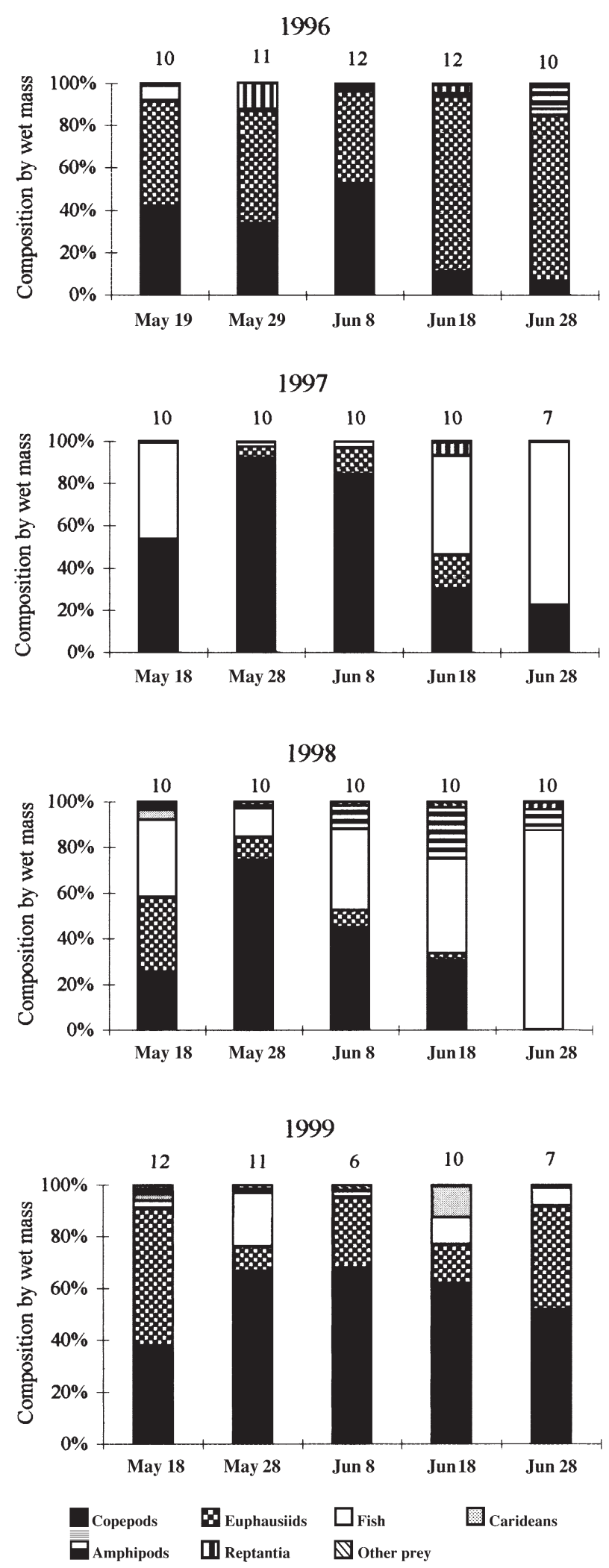

Fig. 4. Ptychoramphus aleuticus. General composition of nestling diet at Triangle Island from mid-May to the end of June, 1996 to 1999. Sample size indicated above each bar
1997 or 1998, Tukey's HSD; $\mathrm{p}<0.001$ ), but in that year mainly $T$. inspinata and $T$. spinifera were consumed. Fishes predominated in the diet in 1998 (Tukey's HSD; $\mathrm{p}<0.05$ ), and this group was also important late in 1997 when it contributed $30 \%$ by mass.

In addition to variation between years, the contribution of Neocalanus cristatus to the diet also varied within a single breeding season (Fig. 4). In both 1997 $\left(F_{4,42}=5.47, \mathrm{p}<0.01\right)$ and in $1998\left(F_{4,45}=5.89, \mathrm{p}<0.01\right)$ significant seasonal declines in the importance of $N$. cristatus were observed. Despite being present at extremely high levels early in 1997 ( $\geq 90 \%$ by mass), $N$. cristatus importance declined precipitously from mid-June, falling to $22 \%$ by the final sampling period. In both 1996 and 1998 the overall importance was lower, and the species was either completely absent or present at very low levels later in the season (Fig. 4). During all sampling periods in 1999, copepods contributed $>55 \%$ by mass to the nestling diet.

The seasonal decline of copepods in both 1997 and 1998 corresponded with an increased importance of fishes (1997: $F_{4,42}=6.56, \mathrm{p}<0.001 ; 1998: F_{4,45}=6.45$, $\mathrm{p}<0.001)$. In 1997, all fishes identified were rockfish Sebastes spp., but a wider variety of fish taxa were preyed upon in 1998, particularly late in the season. In excess of $75 \%$ of the fishes taken between 8 and 18 June 1998 were rockfish spp., but this proportion decreased to $50 \%$ on 28 June when Irish lords Hemilepidotus spp. and flatfishes Pleuronectid spp. contributed 27 and $17 \%$, respectively, to overall mass.

\section{Relationships between adult provisioning and chick growth rates}

Correlations were used to explore relationships between adult provisioning performance (gauged by average daily provisioning rates and the total food delivered) and chick growth rates. In each year, analyses were run for 20 to $40 \mathrm{~d}$ old chicks, but also for chicks aged 15 to 35 d in 1996, 1997 and 1999 (there were insufficient data for a 1998 comparison). In 1996, 1997 and 1999, provisioning and growth were positively related for chicks aged 20 to $40 \mathrm{~d}$, but the relationship was strongest in 1999 (Fig. 5). Rates of provisioning and growth were unrelated in 1998 ( $\mathrm{r}=0.17$, $\mathrm{p}=0.687, \mathrm{n}=8$ ). In both 1996 and 1999, growth from 20 to $40 \mathrm{~d}$ was also strongly related to the total food received, but this was not the case in 1997 ( $\mathrm{r}=0.41, \mathrm{p}=$ $0.196, \mathrm{n}=11)$ and there were too few data $(\mathrm{n}=3)$ to evaluate the relationship in 1998 (Fig. 5). For 15 to 35 d-old chicks, provisioning and growth were unrelated in 1997 ( $\mathrm{r}=0.41, \mathrm{p}=0.117, \mathrm{n}=16)$, but there was a significant positive relationship between growth and the total food received $(r=0.68, p<0.05, n=9)$. In both 
1996 and 1999 results, for 15 to 35 d old chicks were similar to those above, with positive relationships between both growth and provisioning (1996: $\mathrm{r}=0.53$, $\mathrm{p}<0.05, \mathrm{n}=22 ; 1999: \mathrm{r}=0.83, \mathrm{p}<0.01, \mathrm{n}=11$ ), and growth and the total food received (1996: $\mathrm{r}=0.62$, $\mathrm{p}<0.05, \mathrm{n}=11 ; 1999: \mathrm{r}=0.66, \mathrm{p}<0.05, \mathrm{n}=10$ ).

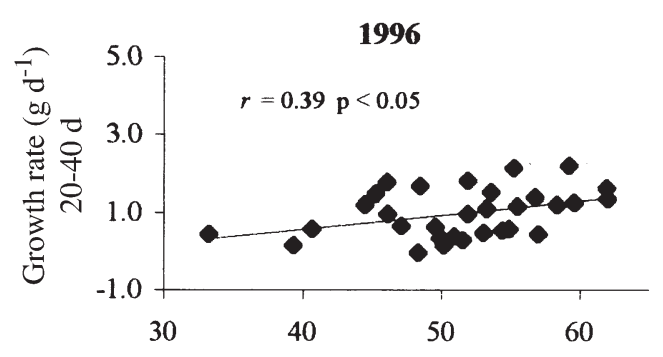

Average provisioning rate $\left(\mathrm{g} \mathrm{d}^{-1}\right)$

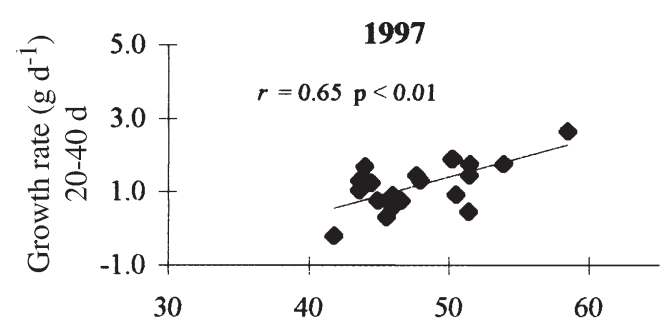

Average provisioning rate $\left(\mathrm{g} \mathrm{d}^{-1}\right)$

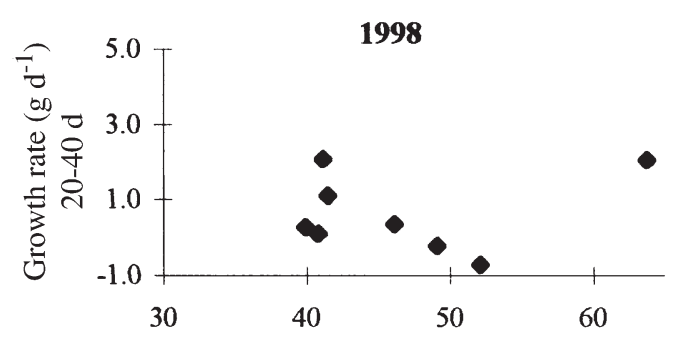

Average provisioning rate $\left(\mathrm{g} \mathrm{d}^{-1}\right)$

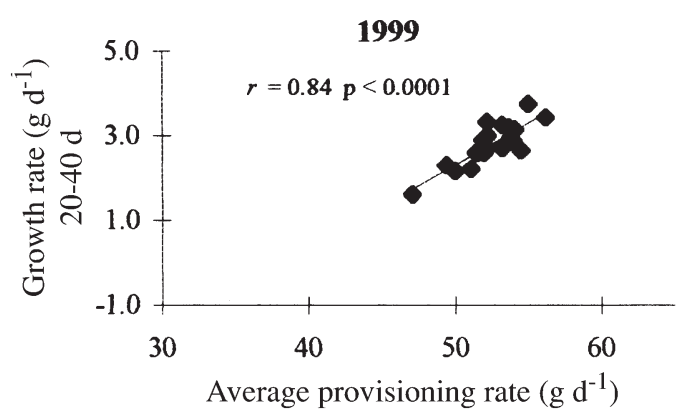

\section{DISCUSSION}

Between 1996 and 1999, substantial within- and between-year variability in the provisioning and growth of Cassin's auklet nestlings paralleled variation in the composition of the diet. The highest provisioning
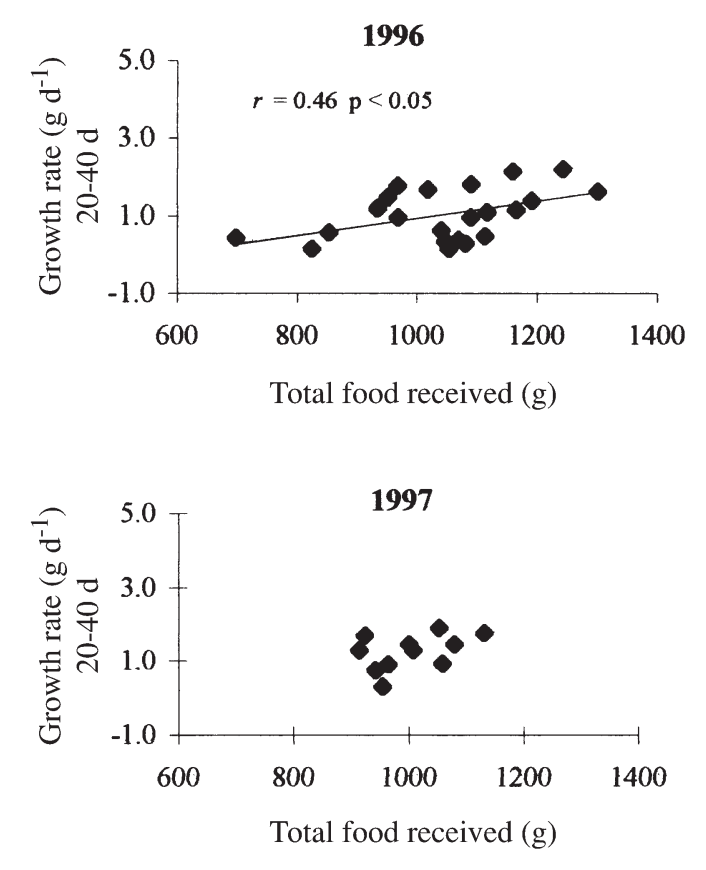

Total food received $(\mathrm{g})$
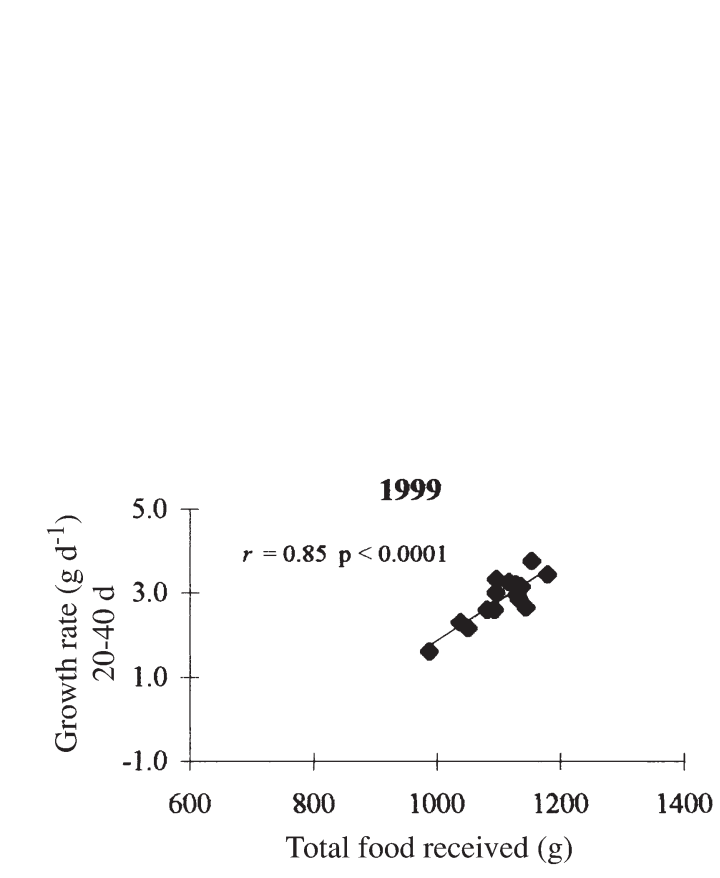

Fig. 5. Ptychoramphus aleuticus. Relationships between chick growth rates and both average provisioning rates $\left(g\right.$, $\mathrm{d}^{-1}$; left-hand graphs) and the total food delivered to chicks (right-hand graphs), 1996 to 1999. Regression lines are indicated only for significant correlations 
and chick growth rates were observed in 1999 (and early in 1997), when the copepod Neocalanus cristatus formed the bulk of the diet. Chick growth was poor throughout 1996 and 1998, and also late in 1997, when availability of $N$. cristatus around Triangle Island was apparently reduced. Cross-shelf plankton surveys near Triangle Island indicated that the abundance of $N$. cristatus was substantially higher in May 1999 than in May 1998 (D. Mackas \& D. Welch, Department of Fisheries and Oceans, Canada, pers. comm.), and radio telemetry work conducted in 1999 revealed that Cassin's auklets were foraging in areas with the highest concentrations of copepods (Boyd et al. 2000). When copepods are unavailable, adults deliver alternate prey to chicks. In 1996, euphausiids replaced $N$. cristatus in the nestling diet, while late in 1997 and throughout 1998 fishes predominated in its absence. The lowest daily provisioning rates were observed when rockfish spp. predominated in diet. Low provisioning rates coupled with lower rockfish energy density $\left(5200 \mathrm{cal} \mathrm{g}^{-1}, \mathrm{n}=3\right.$ vs $6236 \mathrm{cal} \mathrm{g}^{-1}, \mathrm{n}=3$ for $N$. cristatus at Triangle Island: Vermeer \& Cullen 1982) probably explained poor chick growth. Growth was also poor in 1996, despite high provisioning rates. Again, relatively low prey energy densities $(4800 \mathrm{cal}$ $\mathrm{g}^{-1}$ for Euphausia pacifica and 4700 to $5200 \mathrm{cal} \mathrm{g}^{-1}$ for Thysanoessa spinifera from May to July: Mooney 1999), and potentially low assimilation efficiencies (e.g. Kirkwood \& Robertson 1997), might help to explain poor chick growth in that year. Provisioning and growth were consistently high throughout 1999 when $N$. cristatus predominated in the diet. In fact, further diet sampling in 1999 indicated that parents continued to deliver $N$. cristatus to chicks through to mid-July (Bertram et al. 2001).

Parents might be expected to select prey which provide the greatest return for energy expended. Compared with relatively mobile small fishes and euphausiids, copepods are large, slow moving, concentrated at the surface and, being colored orange, are also visually conspicuous. During spring and early summer copepods are the dominant zooplankton subgroup off the west coast of Vancouver Island, contributing $>40 \%$ to total zooplankton biomass (Mackas \& Galbraith 1992). Neocalanus cristatus is the largest copepod found in pelagic waters of the subarctic North Pacific, and it shows a strong pattern of seasonal vertical migration. Copepodites overwinter at depths $>500 \mathrm{~m}$, where they mature, mate and spawn the subsequent spring (Mackas \& Galbraith 1992). Young nauplii migrate to the upper water column (0 to $100 \mathrm{~m}$ ) to feed and grow, and then become available to diving seabirds such as Cassin's auklets which typically forage in the upper $30 \mathrm{~m}$ (Burger \& Powell 1990). The copepod surface period lasts approximately $60 \mathrm{~d}$, by which time C5 copepodites have attained sufficient size and lipid reserves to survive the winter at depth. Ocean climate warming over the past $20 \mathrm{yr}$ has caused a significant seasonal advance in the timing of peak $N$. plumchrus biomass in the North Pacific (Mackas et al. 1998), a species that has a similar seasonal cycle to N. cristatus.

Bertram et al. (2001) suggested that extreme variability in physical oceanography from 1996 to 1999 helped to explain variation in seabird reproductive performance at Triangle Island. Data collected between 1975 and 1999 indicated that in years when ocean warming occurred relatively late and SSTs in April were cold (as in 1997 and 1999), Cassin's auklet nestlings grew more rapidly than in years such as 1996 and 1998 when spring was early and warm. Bertram et al. (2001) suggested that a mismatch between the timing of peak zooplankton availability and the Cassin's auklet breeding season could explain some of the performance differences between years. It was proposed that when spring is early and warm Neocalanus cristatus populations both peak and end early, thus effectively reducing the time that they are available to breeding Cassin's auklets. Supporting this in both 1996 and 1998, there was a strong negative relationship between hatch date and growth rate for individual chicks; that is, parents that bred earlier in the season produced chicks with significantly higher growth rates than those that bred later. The seasonal decline in growth rates in these years matched the disappearance of $N$. cristatus from the diet. In contrast, in 1997 and 1999 there was either a limited (1997) or no (1999) seasonal decline in chick growth rates. Spring was relatively late and cold in these years, and $N$. cristatus was both more important in the diet overall and, at least in 1999, persisted as the most important prey consumed throughout chick-rearing.

\section{Relationship between adult provisioning and chick growth}

We observed inter-year differences in the relationship between adult provisioning and chick growth. In 1999, diet composition was relatively constant through time, and there was a strong positive relationship between provisioning and growth. In 1997, a dietary shift from copepods to fish in the last 2 wk of June coincided with a weaker, but positive, relationship. Temporal variation in the diet was maximal in 1998, when provisioning and growth were unrelated. These results indicate that even closely correlated variables, such as provisioning and growth, can be confounded by a number of factors. Our study focuses on variability in the quantity and the quality of food delivered to chicks, 
but the age, breeding experience or the 'quality' of adults may also interact to influence both provisioning strategies and breeding outcomes (Cobley et al. 1998, Wendeln \& Becker 1999). It is noteworthy that even in poor years such as 1996 and 1998 Cassin's auklets both attempted to breed (although at a reduced rate in 1998: Bertram et al. 2001), and expended substantial effort during the chick-rearing period feeding their nestlings almost every night. Chicks fledged at low body mass in both of these years, but at 65 and $47 \%$, the fledging rate (chicks hatched/chicks fledged) was still relatively high.

\section{Predicting provisioning rates from daily weighing of chicks}

It was of considerable practical interest to determine if equations developed from periodic weighing in one year could be used to estimate provisioning rates of Cassin's auklets in years (or at other sites) where weighings were conducted only once per day. We found no support for this approach, because provisioning rates predicted from year-specific and non-yearspecific equations were significantly different. Net mass gain from a given quantity of food depends on a variety of factors including the feeding frequency, size, energy density and digestibility of the food, and the body mass and/or condition of the chick. The greater the variations of the above factors from the years or sites at which predictive equations were developed, the poorer the resulting provisioning estimates would be. Our results demonstrate that both daily and overnight weighing is essential for obtaining realistic estimates of food delivery rates.

Within a particular year, we found lower age-specific masses for chicks that were weighed each day, but only in years when food availability was apparently high (i.e. 1997 and 1999). There was no detectable handling effect in either 1996 or 1998, when chicks were presumably already food-stressed. The negative effects observed in 1997 and 1999 were similar to those reported by Morbey \& Ydenberg (1997), who also found the growth of Cassin's auklet chicks at Triangle Island to be significantly depressed by frequent handling.

\section{Adult response to chick requirements}

While documenting natural variation between years in the provisioning performance of Cassin's auklets, we have also found annual differences in the adult's ability (or willingness) to respond to chick needs. We suggest that such differences could reflect prey availability at sea. At-sea surveys indicated that Neocalanus cristatus was more abundant within the birds foraging zones in May 1999 than in May 1998 (Boyd et al. 2000, D. Mackas \& D. Welch, Department of Fisheries and Oceans pers. comm.). A dietary shift and high chick mortality further indicate that $N$. cristatus was less available to the birds in 1998. Antarctic prions Pachyptila desolata also showed variable response to chick needs, depending on the relative food availability at sea (Weimerskirch et al. 1999). Adult prions increased provisioning to undernourished chicks when food availability was high, while they showed no response to chick needs in years when food was apparently more difficult to find. Even for a single species then, the answer to parental regulation capacity can depend on the year (and also probably on the site) at which the question is asked, as adults may have a greater capacity to respond in some years than in others.

A complex variety of factors relating to the foraging ecology and to the adults themselves (including their quality, age, experience and condition), in addition to the availability of prey, must influence whether or not adults respond to chick requirements. Recent work (Weimerskirch et al. 1994, 1997, Granadeiro et al. 1999) has emphasized the importance of documenting attendance patterns of individual adults when addressing such questions, and this appears to be especially important when the assessments are made indirectly. For example, Cory's shearwaters Calonectris diomedea were found to respond to chick needs when serial weighing data were combined with adult attendance records, but this effect was not detected from the weighing data alone. For some pelagic Procellariiformes, provisioning effort is independent of chick requirements but under the strict control of adult body condition (Chaurand \& Weimerskirch 1994, Weimerskirch et al. 1994, 1995, 1997, Duriez et al. 2000). Separating the contributions of variation in food availability and adult body condition, and identifying potential interactions between the two, represents a challenge for future research.

Acknowledgements. Thanks to the many volunteers and technicians who helped collect mass data from Cassin's auklets at Triangle Island between 1996 and 1999. We are very grateful to Moira Galbraith from the Institute of Ocean Sciences, Sidney, British Columbia, for identification of Cassin's auklet prey items. The British Columbia Ministry of Environment Lands and Parks provided the permit to work on Triangle Island, and the Canadian Coast Guard provided essential logistical support. This research was funded by the Nestucca Oil Spill Trust Fund, the Center for Wildlife Ecology at Simon Fraser University, the Natural Sciences and Engineering Research Council of Canada, the Canadian Nature Federation and the Canadian Wildlife Service. The Canadian Climate Change Action Fund and Environment Canada's Science Horizons Internship Program provided additional funds for analysis and manuscript preparation. 


\section{LITERATURE CITED}

Ainley DG, Sydeman WJ, Hatch SA, Wilson UW (1994) Seabird population trends along the west coast of North America: causes and the extent of regional concordance. Stud Avian Biol 15:119-133

Ainley DG, Spear LB, Allen SG (1996) Variation in the diet of Cassin's auklet reveals spatial, seasonal and decadal occurrence patterns of euphausiids off California, USA. Mar Ecol Prog Ser 137:1-10

Bertram DF, Cowen L, Burger AE (1999) Use of radar for monitoring colonial burrow-nesting seabirds. J Field Ornithol 70:145-157

Bertram DF, Jones IL, Cooch EG, Knechtel HA, Cooke F (2000) Survival rates of Cassin's and rhinoceros auklets at Triangle Island, British Columbia. Condor 102:155-162

Bertram DF, Mackas DL, McKinnell SM (2001) The seasonal cycle revisited: interannual variation and ecosystem consequences. Prog Oceanogr 49:283-307

Bolton M (1995) Food delivery to nestling storm petrels: limitation or regulation? Funct Ecol 9:161-170

Boyd WS, Ryder JL, Shisko SG, Bertram DF (2000) At-sea foraging distributions of radio-marked Cassin's auklets breeding at Triangle Island, BC. Canadian Wildlife Service, Pacific and Yukon Region, Delta, BC, Tech Rep Ser 353

Burger AE, Powell DW (1990) Diving depths and diet of Cassin's Auklet at Reef Island, British Columbia. Can J Zool 68:1572-1577

Chaurand T, Weimerskirch H (1994) The regular alternation of short and long foraging trips in the blue petrel Halobaena caerulea: a previously undescribed strategy of food provisioning in a pelagic seabird. J Anim Ecol 63: 275-282

Cobley ND, Croxall JP, Prince PA (1998) Individual quality and reproductive performance in the grey-headed albatross Diomedea chrysostoma. Ibis 140:315-322

Duriez O, Weimerskirch H, Fritz H (2000) Regulation of chick provisioning in the thin-billed prion: an interannual comparison and manipulation of parents. Can J Zool 78: $1275-1283$

Granadeiro JP, Burns MD, Furness RW (1999) Food provisioning to nestling shearwaters: why parental behaviour should be monitored? Anim Behav 57:663-671

Hamer KC, Hill JK (1993) Variation and regulation of meal size and feeding frequency in cory's shearwater Calonectris diomedea. J Anim Ecol 62:441-450

Hamer KC, Thompson DR (1997) Provisioning and growth rates of nestling fulmars Fulmarus glacialis: stochastic variation or regulation? Ibis 139:31-39

Kirkwood R, Robertson G (1997) The energy assimilation efficiency of emperor penguins, Apenodytes forsteri, fed a diet of Antarctic krill, Euphausia superba. Physiol Zool 70(1):27-32

Mackas DL, Galbraith M (1992) Zooplankton on the west coast of Vancouver Island: distribution and availability to marine birds. Can Wildl Serv, Occas Pap 75:15-21

Mackas DL, Goldblatt R, Lewis AG (1998) Interdecadal variation in developmental timing of Neocalanus plumchrus populations at Ocean Station P in the subarctic North Pacific. Can J Fish Aquat Sci 55:1878-1893

Manuwal DA (1974) The natural history of Cassin's auklet Ptychoramphus aleuticus. Condor 76:421-431

Manuwal DA, Thoresen AC (1993) Cassin's auklet Ptychoramphus aleuticus. In: Poole A, Gill F (eds) The birds of

Editorial responsibility: Otto Kinne (Editor), Oldendorf/Luhe, Germany
North America. No. 50. The Academy of Natural Sciences, Philadelphia and The American Ornithologists' Union, Washington, DC, p 1-18

Mooney JR (1999) Distribution, energetics, and parasites of euphausiids in Prince William Sound, Alaska. MSc Thesis. University of Alaska Fairbanks

Morbey YE, Ydenberg RC (1997) Intraspecific variability in nestling growth and fledging behavior of Cassin's auklets at Triangle Island, British Columbia. Condor 99:361-371

Phillips RA, Hamer KC (2000) Periodic weighing and the assessment of meal mass and feeding frequency in seabirds. J Avian Biol 31:75-80

Ricklefs RE (1984) Meal sizes and feeding rates of Christmas shearwaters and Phoenix petrels on Christmas Island, Central Pacific Ocean. Ornis Scand 15:16-22

Ricklefs RE (1987) Response of adult Leach's storm-petrels to increased food demand at the nest. Auk 104:750-756

Ricklefs RE, Day CH, Huntington CE, Williams JB (1985) Variability in feeding rate and meal size of Leach's stormpetrel at Kent Island, New Brunswick. J Anim Ecol 54: 883-898

Rodway MS, Lemon MJF, Summers KF (1990) British Columbia seabird colony inventory: report \#4-Scott Islands. Census results from 1982 to 1989 with reference to the Nestucca oil spill. Canadian Wildlife Service, Pacific and Yukon Region, Delta, BC, Tech Rep Ser 86

Roemmich D, McGowan J (1995) Climactic warming and the decline of zooplankton in the California Current. Science 267:1324-1326

Sydeman WJ, Hobson KA, Pyle P, McLaren EB (1997) Trophic relationships among seabirds in central California: combined stable isotope and conventional dietary approach. Condor 99:327-336

Vermeer K (1981) The importance of plankton to Cassin's auklets during breeding. J Plankton Res 3:315-329

Vermeer K (1985) A five-year summary (1978-1982) of the nestling diet of Cassin's auklets in British Columbia. Can Tech Rep Hydrogr Ocean Sci 56

Vermeer K (1987) Growth and nestling periods of Cassin's auklets: adaptations of planktivorous auklets to breeding in northern latitudes. Can Tech Rep Hydrogr Ocean Sci 93

Vermeer K, Cullen L (1982) Growth comparison of a plankton- and fish-feeding alcid. Murrelet 63:34-39

Ware DM, McFarlane GA (1989) Fisheries production domains in the Northeast Pacific Ocean. Can Spec Publ Fish Aquat Sci 108:359-379

Weimerskirch H, Chastel O, Chaurand T, Ackerman L, Hindermeyer X, Judas J (1994) Alternate long and short foraging trips in pelagic seabird parents. Anim Behav 47:472-476

Weimerskirch H, Chastel O, Ackerman L (1995) Adjustment of parental effort to manipulated foraging ability in a pelagic seabird, the thin-billed prion Pachyptila belcheri. Behav Ecol Sociobiol 36:11-16

Weimerskirch H, Cherel Y, Cuenot-Chaillet F, Ridoux V (1997) Alternate foraging strategies and resource allocation by male and female wandering albatrosses. Ecology 78:2051-2063

Weimerskirch H, Fradet G, Cherel Y (1999) Natural and experimental changes in chick provisioning in a longlived seabird, the Antarctic prion. J Avian Biol 30:165-174

Wendeln H, Becker PH (1999) Effects of parental quality and effort on the reproduction of common terns. J Anim Ecol 68:205-214

Submitted: December 7, 2000, Accepted: July 26, 2001

Proofs received from author(s): February 20, 2002 